\title{
Geleneksel Tibba Etik ve Hukuk Yönü ile Bakış
}

\author{
Overview of Traditional Medicine Ethics and Legal Aspects
}

\author{
Mahmut Tokaç \\ İstanbul Medipol Universitesi Tip Fakültesi Öğretim Üyesi \\ Yazıșma Adresi / Correspondence: \\ Dr. Öğr. Üyesi Mahmut Tokaç \\ İstanbul Medipol Universitesi Tip Fakültesi, İstanbul \\ E-mail: : mtokac@medipol.edu.tr \\ Orcid \\ Mahmut Tokaç : https://orcid.org/0000-0002-3051-0074 \\ Kabul Tarihi / Accepted : 21-06-2019 \\ Yayın Tarihi / Online Published: 30-09-2019
}

Geliş Tarihi / Received : 18-04-2019

Tokaç M. Geleneksel Tıbba Etik ve Hukuk Yönü ile Bakış, J Biotechnol and Strategic Health Res. 2019;3(Özel Sayı):155-160 DOI: bshr.555783

Özet

Geleneksel ve Tamamlayııı Tıp (GETAT) uygulamaları 40 yıldan fazladır. "DSÖ” aracılı̆̆ıyla modern batı ülkelerinin gündeminde yer almasına karșın ülkemizde bu alan ancak 2014 yllında mevzuat düzenlemesi yapıldıktan sonra gündem olabilmiștir. Bu mevzuat düzenlemeleriyle birlikte etik ve hukuki yönü ile GETAT uygulamalarına bakılması gerekmektedir. Bu makalemizde GETAT uygulamalarında karşılaşılabilecek etik sorunlar ile hukuksal sorumluluklar irdelenecektir.

Anahtar GETAT, Geleneksel Tip, Tamamlayıcı Tip, Etik, Hukuk

Kelimeler

Abstract

Although Traditional and Complementary Medicine (T⿺CM) applications have been on the agenda of modern western countries for more than 40 years through WHO, this field has become an agenda in our country only after the regulation was made in 2014. Ethical and legal aspects and GETAT applications should be considered together with these legislations. In this article, ethical problems and legal responsibilities that may be encountered in GETAT applications will be discussed.

Keywords T®CM, Traditional Medicine, Complementary Medicine, Medical Ethics, Legal condition 


\section{Tibbi Deontoloji ve Sorumluluk}

Tıbbi Deontoloji, hekimlerin ve diğer sağlık meslek mensuplarının tıbbî uygulamaları esnasında uymaları gereken kuralların tümüne verdiğimiz isimdir. Bu kurallar ister yazılı ve maddi yaptırımı olan kurallar olsun (hukuk), isterse yazılı olmayan ve maddi yaptırımı bulunmayan kurallar olsun (ahlâk) kendimizi uymakla yükümlü hissederiz. Özellikle de hukuk, kurallarına uymadığımız taktirde yaptırımları ile bizleri uymaya zorlamaktadır. İşte buna hukuk dilinde "Tibbi Sorumluluk" diyoruz ki sağlık mesleği mensuplarının tıbbi uygulamaları esnasında kasıtla ya da mesleki bir taksirle verdiği zarardan dolayı sorumlu tutulmasidir.

Ceza Hukuku açısından sağlık meslek mensubunun kasıttan doğan sorumluluğu diğer kimselerin kasıtla işledikleri suçlardaki sorumluluğundan farklı değildir. Taksirle işlenen suçlarda ise herkes kendi kusuru oranında sorumlu olur. Sağlık hizmeti sunumunda "malpraktis" olarak isimlendirilen "tıbbi uygulama hatası" olması halinde (yani meslekî cüret, meslek ve sanatta acemilik, kurallara uymamak, tedbirsizlik, dikkatsizlik, özensizlik ya da ihmal durumlarından herhangi birinin varlığının bilirkişiler tarafından tespit edilmesi durumunda) bir insanın ölmesi veya yaralanması gerçekleşmişse sorumlu tutulan sağlık meslek mensupları Ceza Mahkemelerinde Türk Ceza Kanunundaki (TCK) “Taksirle adam öldürme” veya "Taksirle yaralama” suçlarından yargılanır.

Ceza sorumluluğu yanında hukuk (tazminat) sorumluluğu da vardır ki bu da medeni hukukta bir kişiye zarar veren kimsenin zararı tazmin etmesi anlamındadır. Bu sorumluluklar ceza ve hukuk mahkemelerinde yapilan yargılamalar sonucunda karara bağlanır. Ayrıca idareye ve meslek örgütüne karşı idari (mesleki) sorumluluklar da söz konusudur ki bunlar idari soruşturmalar yoluyla neticelendirilir. ${ }^{1}$

\section{Geleneksel ve Tamamlayıcı Tıp (GETAT) Uygulamalarında Sorumluluk}

Bütün tıbbi uygulamalarda olduğu gibi GETAT uygulamalarında da sağlık meslek mensuplarının uymaları gereken kurallar vardır ve bu kuralların ihlâl edilmesi durumunda karşılaşacakları sorumluluklar olacaktır.

Sağlığın anayasası kabul edebileceğimiz 1219 sayılı Tababet ve Şuabatı San'atlarının Tarzı İcrasına Dair Kanunun Ek 13. maddesinde “Tabipler ve diş tabipleri dişındaki sağlık meslek mensupları hastalıklarla ilgili doğrudan teşhiste bulunarak tedavi planlayamaz ve reçete yazamaz." denilerek tedavi yetkisi sadece hekimlere verilmiştir. Bu yüzden GETAT Eğitim Standartlarında sadece tabip ve diş tabiplerine yönelik eğitimlerin standartlarını belirlenmiştir.

Yine 1219 sayılı Kanunun 25. maddesinde "Diploması olmadığı hâlde, menfaat temin etmek amacına yönelik olmasa bile, hasta tedavi eden veya tabip unvanını takınan şahıs iki yıldan beş yıla kadar hapis ve bin güne kadar adlî para cezası ile cezalandırılır.” şeklinde bir ceza hükmü mevcuttur.

$\mathrm{Bu}$ hükümlere istinaden GETAT uygulayıcılarının hekim olma zorunluluğu yanında GETAT uygulamalarının temel mevzuatı olan Geleneksel ve Tamamlayıcı Tip Uygulamaları Yönetmeliğine göre de Sağlık Bakanlığı tarafından onaylanmış uygulama sertifikası sahibi olmaları ve uygulama yeri için de Bakanlığın izini almış olmaları gerekli$\operatorname{dir}^{2,3}$

40 yıldan fazladır DSÖ aracılığıyla modern batı ülkelerinin gündeminde yer alan GETAT uygulamaları ülkemizde ancak 2012 yılında 1219 sayılı Kanunda yapılan değişiklik sonrasında 27/10/2014 tarihli ve 29158 sayılı Resmî Gazetede yayımlanan Geleneksel ve Tamamlayıcı Tip Uygulamaları Yönetmeliği'nden sonra gündem olabilmiştir. ${ }^{4} \mathrm{Bu}$ alandaki mevzuat düzenlemeleri çok yeni olduğu için bu uygulamalardan doğacak sorumlulukla ilgili olası soru ya da sorunlar aşağıda sıralanmıştır: 
- GETAT uygulamaları ile klasik tıbbın hastalık sınıflamaları aynı olmadığı için hastalıklara müdahaleye yetkili uzmanlık alanları ayrımı nasıl yapılabilecektir? Klasik tıpta bile uzmanlık alanları arasında yetki açısından tam bir ayrım yapılamazken GETAT uygulayıcısı hekimler arasında uzmanlık ayrımı yapılabilecek midir?

- GETAT uygulayıcısı pratisyen hekimlerin hangi tür hastalıkları tedavi edebilme yetkisi olacaktır?

- GETAT uygulayıcısı uzman hekimler aynı zamanda bir pratisyen hekim olmaları dolayısıyla pratisyen hekimlerin sahip olduğu yetkilere sahip olmalarının önünde bir engel var midır?

- Hekimlerin klasik tıp uygulamaları için yapılmış olan Tibbi Kötü Uygulamaya İlişkin Mesleki Sorumluluk Sigortası kapsamına GETAT uygulamaları da dahil edilebilecek midir?

- $\quad$-GETAT uygulanan bir hastada kötü bir sonuç oluşursa bu durum tıbbî uygulama hatası/malpraktis olarak değerlendirilecek midir?

GETAT uygulamalarına ilişkin hukuki durum hakkında özetle şunları söyleyebiliriz:

Klasik tıp uygulamalarında bir pratisyen hekimin hangi tür hastalıkları tedavi edebilme yetkisi varsa GETAT sertifikalı pratisyen hekimlerinin de aynı tür hastalıkları tedavi edebilmelerinin önünde yasal bir engel yoktur.

GETAT sertifikalı uzman hekimlerin alanlarıyla ilgili uygulamaları yapmaya yetkilidirler. Herhangi bir dalda uzmanlığı olan hekimler klasik tıp uygulama açısından aynı zamanda bir pratisyen hekimin uygulayabildiği haklara sahip olmaları dolayısıyla GETAT sertifikalı pratisyen hekimlerin sahip oldukları uygulama yetkilerine de sahiptirler.

GETAT uygulamalarının klasik tıp uygulamalarıyla birlikte (entegre) yapıldığı ve zarar ortaya çıktığı durumlarda zararın hangi uygulamadan dolayı olduğunu tespit oldukça zordur. Böyle bir durumda her iki uygulayıcı taraf bir- birini suçlayacaktır. Eğer konu mahkemeye intikal etmişse bilirkişilerin GETAT uygulamaları hakkında bilgisi olmaması durumunda verilen karar objektif olamayacaktır. Bu tür durumlarda bilirkişi heyetinin içinde hem klasik tıp uygulayıcıları hem de GETAT uygulayıcıları bulunması gereklidir.

GETAT uygulamalarından deneme kapsamına girenlerin tespiti iyi yapılmalı ve 9.3.2019 tarihli ve 30709 sayılı Resmi Gazetede yayımlanarak yürürlüğe giren Geleneksel ve Tamamlayıcı Tıp Uygulamalarının Klinik Araştırmaları Hakkında Yönetmelik hükümlerine uygun şekilde gerekli izinler alındıktan sonra yapılmalıdır. Aksi taktirde GETAT uygulayıcısı hekimler TCK’nun 90. maddesinde yer alan izinsiz deney yapmak suçundan 1 yıldan 3 yıla kadar hapis cezasina muhatap olacaklardır.

Tibbi Kötü Uygulamaya İlişkin Mesleki Sorumluluk Sigortası kapsamındaki kendi uzmanlık alanındaki hekimlik uygulamaları dışında GETAT uygulaması da yapan sertifika sahibi hekimlerin, sigorta poliçelerine ek olarak bu uygulamalarını da yazdırmaları gereklidir. Ancak uygulamada sigorta şirketleri tarafından uzmanlık alanlarına göre belirlenmiş ifadeler dışında başka bir ek şimdilik yapilmamaktadır. GETAT uygulayan hekimlerin ileride sorun yaşamamaları için sigorta konusunda GETAT uygulamalarını içeren bir düzenleme acilen hayata geçirilmelidir.

\section{Tıp Etiği}

Tıp Etiği sağlık hizmetlerinin sunucuları ile (kişi ya da kurum olabilir) sağlık hizmetlerini alanların (hastalar ya da yakınları) beklenti ve değer yargıları arasındaki farklılıklardan doğan ikilemleri çözümleyebilme yöntemleridir ki bunun için de bir anlamda karayolunda bizlere yön gösteren trafik levhaları gibi işlev gören ilkeler devreye girmektedirler.

Tıp Etiğinin 4 Temel İlkesi vardır:

1. Yararlılık (Beneficence)

2. Zarar vermeme (Non-maleficence) 
3. Adalet (Justice)

4. Özerkliğe saygı (Autonomy).

Yararlılık hekimlerin ve diğer sağlık meslek mensuplarının yapacakları tüm tıbbi eylemlerin mutlaka yararlı olması demektir. Yani her tıbbi eylemin mutlaka gereklilik şartı vardır ki tıp dilinde buna endikasyon diyoruz. Endikasyonu olmadan gereksiz ve yararsız hiçbir tıbbi eylemin yapılmaması anlamına gelir.

Zarar vermeme ilkesi tıbbın temel prensibi olan yapılan tıbbi eylemlerin zarar vermemesidir. Ancak yararlı olması amacıyla yaptığımız tıbbi eylemler aynı zamanda zarar verebilme potansiyelini de barındırır. Bu gibi durumlarda yarar/zarar dengesinin bariz şekilde yarar tarafına üstün olmasına dikkat edilmesi gereklidir. Yararlılık her zaman bir eylemi gerektirirken zarar vermeme bazı durumlarda bir eylemsizlik olabilir. Yani zarardan emin değilsek hiç müdahale etmemek müdahaleden daha önemlidir.

Adalet ilkesi herkese hak ettiğini vermek demektir. Şartların eşit olduğu durumlarda eşit davranmamız adaletin gereği iken şartların eşit olmadığı durumlarda eşit davranmak adaletsizlik olabilmektedir. Bu durumda aciliyeti olana öncelik vermek adaletin gereğidir.

Özerkliğe saygı ilkesi hastanın kendisi hakkında tıbbi kararları kendisinin vermesidir. Ancak bu kararı verebilmesi için yeterli bilgiye sahip olması gerekir. Halbuki sağlık alanı, hizmet alanların gerekli olan bilgileri hizmet verenlerden almak zorunda kaldıkları bir alandır. Bu itibarla kişinin kendisi hakkında karar verebilmesi için hizmeti verenlerin sahip oldukları bilgileri hastalarına anlayacakları bir dille ve yeterli bir şekilde aktarmaları, bu bilgilendirmenin ardından yeterli zaman verildikten sonra kendisinin kararına göre tıbbi müdahalenin yapılması gerekmektedir. ${ }^{5,6}$

\section{GETAT Uygulamalarında Yaşanan Etik Sorunlar}

Klasik tıp uygulamaları için geçerli olan Tıp Etiğinin 4 Te- mel İlkesi GETAT uygulamaları açısından da geçerlidir.

GETAT uygulamaları ülkemizde yeni şekillenmeye başladığı için GETAT uygulamaları esnasında yaşanan etik sorunlar da yeni yeni karşımıza çıkmaktadır. GETAT uygulamaları sırasında ortaya çıkabilecek sorunları tıp etiğinin temel ilkeleri açısından aşağıdaki sorularla belirleyebiliriz: Yararlılık ilkesi açısından;

- GETAT uygulamalarında hasta yararı var midır? (Bu soru peşinden "hasta yararı kavramından kastedilenin ne olduğu?" sorusunu da getirir.)

- Tam bir iyileşme mi olması gerekir hasta yararı olduğunu söyleyebilmemiz için? (Klasik tıp uygulamalarının akut hastalıklardaki yadsınamaz başarısı yanında kronik hastalıklarda tam iyileşme sağlayamayıp kısmi iyileşme sağladığı durumlar olduğu gibi GETAT uygulamalarının da tam iyileşme sağlanamayıp kısmen iyileşme sağlanması durumunda hasta yararı olmadı$\breve{g}_{1}$ iddia edilebilecek midir?)

- GETAT uygulamalarından yarar gördüğünü söyleyen hastaların beyanlarını ne kadar dikkate alınacaktır?

- GETAT uygulamalarında görülen iyileşme durumlarını (klasik tıpta varlığı kabul edilen plasebo etkisi ile izah etsek bile) hastanın yararına bir durum olarak değerlendirebilir miyiz?

Zarar vermeme ilkesi açısından;

- GETAT uygulamasından dolayı hastanın zarar görmeyeceğinden emin miyiz?

- GETAT uygulamalarının tümü mü hastalara zarar verir yoksa sadece GETAT uygulaması dolayısıyla hastanın klasik tedavileri tamamen bırakması dolayısıyla zarar oluşması ihtimali var mıdır?

- GETAT uygulamalarının zararlı olduğunu iddia edebildiğimiz kadar klasik tıp uygulamalarının ne kadarının zarar vermediğinden gerçekten emin olabiliyoruz?

Özerkliğe saygı ilkesi açısından;

- $\quad$ GETAT uygulaması yapılan hastalar yeterli bilgilendi- 
rilmek suretiyle rızası alınmış mıdır?

- Klasik tıp uygulayıcısı hekimler hastalarına GETAT seçeneklerinin de olduğunu belirtmemesi hastanın bilgilenme hakkının ve dolayısıyla özerkliğini kullanma hakkının ihlali midir?

$\mathrm{Bu}$ ilkeler doğrultusunda şu tespitleri yapabiliriz:

Klasik tıp uygulayıcısı hekimlerin bir kısmı bilim dışı olduğu ve kanıta dayalı olmadığı gerekçesiyle GETAT uygulamalarına şiddetle karşı çıkmaktadırlar. GETAT uygulattıran hastalar azarlanmak korkusuyla hekimlerine bu durumları haber vermemektedirler. Halbuki hastaların hekimlerine bilgi vermeleri hastalığın seyri ve hastanın sağlığı açısından çok önemli bir husustur. Hekimlerin karŞı duruşları hastalarının yaşayabilecekleri olası zararları fark edip önlem alınmasına engel olabilmektedir. Bu yüzden klasik tıp uygulayıcısı hekimlerin hastalarının GETAT uygulattırdıklarını söylemelerini engellemeyecek şekilde davranmaları hastaların yararına olacaktır.

GETAT uygulamaları sonucunda bazı kronik hastalıklarda kullanılan ilaçların dozunda veya miktarında azalma sağlanabilmektedir. Bu da sürekli kullanılacak ilaçlara bağlı yan etki riskinin azaltılması açısından hastaların yararına bir durum olduğu gibi sosyal güvenlik harcamalarını da azaltacak bir durumdur.

Özerkliğe saygı ilkesine uygun davranmanın en önemli şartı hekimin kendi benimsediği tedavi yöntemleri dışında kalan tüm tedavi seçeneklerini artı ve eksileriyle birlikte bildirmesidir. Klasik tıp uygulayıcısı bir hekimin diğer klasik tıp uygulamaları ile yaygın bilinen GETAT uygulamaları hakkında da bilgi vermesi özerkliğe saygı kapsamında gerekli olan bir davranıştır. Yeterli bilgilendirme yapabilmek için hekimlerin uzmanlık alanlarıyla ilgili GETAT uygulamaları hakkında bilgi sahibi olmaları gerekecektir. Aynı şekilde GETAT uygulayıcılarının da diğer GETAT uygulamaları ve klasik tıp uygulamaları hakkında bilgilendirme yapmaları gerekmektedir. Bu kadar kapsamlı bilgilendirme yapılmadan alınacak bir rızanın, özerkliğe saygı ilkesini ihlal etmesi söz konusudur.

En önemli etik problemlerden biri de her iki grubun da genellemeler yapmalarıdır. Klasik tıp uygulayıcılarının toptan red konumunda olmaları ne kadar yanlışsa GETAT uygulayıcılarının da klasik tıp uygulamalarını yok saymaları ve her türlü hastalığı iyi edebilecekleri iddiasında bulunmaları da o derece yanlıştır.,

\section{SONUÇ}

GETAT uygulayıcılarının etik ilkelere uyma konusunda klasik tıp uygulayıcılarıyla aynı ilkelere tabi olmalarına karşılık klasik tıp uygulayıcılarının hukuki sorumluluklarından daha fazla sorumlulukları olması dolayısıyla bu sorumluluklarının farkında olmaları gerekmektedir. Özellikle malpraktis, sigorta kapsamı ve izinsiz deney konularında son derece dikkatli olmaları, ileride yaşanabilecek olumsuzlukları önlemede yardımcı olacaktır. 
Journal of BSHR 2019;3(Özel Sayı):155-160

TOKAÇ. Geleneksel Tipta Etik ve Hukuk

\section{Kaynaklar}

1. Hakeri H. ve ark. "Tip / Sağlık Hukuku Mevzuatı", Seçkin Yayıncllı, Ankara, 2013

2. Somer P., Vatanoğlu-Lutz, E.E. "Geleneksel ve Tamamlayıcı Tip Uygulamaları Yönetmeliğinin Hukuki ve Etik Açıdan Değerlendirilmesi”, Anadolu Kliniği, 2017;22(1):58-65.

3. Tokaç M. "Geleneksel ve Tamamlayıcı Tip Uygulamaları Mevzuatı Hakkında", Hayat Să̆lık, Sağlık ve Sosyal Bilimler Dergisi, 2018;17: 22-25.

4. Tokaç M. "Geleneksel Tibba Akademik Yaklaşım: GETTAM". SD Sağllk Düşüncesi ve Tip Kültürü Dergisi Sonbahar 2013; 28: 82-85.

5. Beauchamp, T.L., Childress, J.F.; "Biyomedikal Etik Prensipleri", (Yedinci Edisyon, Çev: M.Kemal Temel), BETIM, İstanbul, 2017.

6. Cobanoğlu, N. "Tip Etiği", İlke Yayınevi, Ankara, 2007.

7. Tokaç. M. "Geleneksel ve Tamamlayı ı Tip Uygulamalarında Bilgilendirilmiş Olur Formu Nasıl Olmalıdrr?” (Sözel Bildiri), Uluslararast Geleneksel ve Tamamlayıcı Tip Kongresi, İstanbul, 19-22 Nisan 2018.

8. Nișancı Y, Nazlı N, Özkan M, Özcan M.TKD Etik Kılavuzu, Bölüm 7: Alternatif ve Tamamlayıcı Tip ile İlişkilerde Etik, Türk Kardiyol Dern Arș - Arch Turk Soc Cardiol 2009;37 Suppl 3, 33-35. 